\title{
PENGARUH LINGKUNGAN KERJA, FASILITAS KERJA DAN MOTIVASI TERHADAP KINERJA GURU DI YAYASAN PENDIDIKAN AZADIN ANHAR KECAMATAN WAMPU KABUPATEN LANGKAT
}

\author{
${ }^{1}$ Heriati, ${ }^{2}$ Putri Herviana Daulay \\ ${ }^{1}$ Universitas Islam Sumatera Utara, , ${ }^{2}$ Universitas Islam Negeri Sumatera Utara \\ ${ }^{1}$ heriati@gmail.com, ${ }^{2}$ putriherdaulay@gmail.com
}

\begin{abstract}
The formulation of the problem in this study is how the influence of the Work Environment, Work Facilities and Motivation on Teacher Performance at the Azadin Anhar Education Foundation, Wampu subdistrict, Langkat Regency, both partially and simultaneously. The population and sample of this study were all teachers at the foundation, amounting to 37 people. The sampling technique uses total sampling. Data collection techniques used were direct interviews and questionnaires. The results of this study are partially Work Environment variables have a positive and significant effect on Teacher Performance with tcount $>$ ttable, $(5.525>2.04$,), Work Facility variables have a positive and significant effect on Teacher Performance with tcount $>$ ttable, $(2,411>2.04)$ and Motivational Variables have a positive and significant effect on Teacher Performance with tcount> ttable, (3.218> 2.04). Simultaneously the variable Work Environment, Work Facilities and Motivation have a positive and significant effect on Teacher Performance with Fcount> Ftable, (14.558> 2.87). R2 (RSquare) value of 0.540, which means that the variable Work Environment, Work Facilities and Motivation has a positive and significant effect on Teacher Performance at Azadin Anhar Education Foundation, Wampu Subdistrict, Langkat Regency by $54.00 \%$, and the remaining $46.00 \%$, influenced by other factors not examined.
\end{abstract}

Keywords: Work Environment, Work Facilities, Motivation and Teacher Performance

ABSTRAK : Rumusan masalah dalam penelitian ini adalah Bagaimana pengaruh Lingkungan Kerja, Fasilitas Kerja dan Motivasi Terhadap Kinerja Guru di Yayasan Pendidikan Azadin Anhar kecamatan Wampu Kabupaten Langkat baik secara parsial maupun simultan. Populasi dan sampel penelitian ini adalah seluruh guru di yayasan tersebut yang berjumlah 37 orang. Teknik pengambilan sampel menggunakan total sampling. Teknik pengumpulan data yang digunakan adalah wawancara langsung dan angket. Hasil penelitian ini adalah secara parsial variabel Lingkungan Kerja berpengaruh Positif dan signifikan terhadap Kinerja Guru dengan nilai $t_{\text {hitung }}>t_{\text {tabel, }}(5,525>2,04$, ), variabel Fasilitas Kerja berpengaruh Positif dan signifikan terhadap Kinerja Guru dengan nilai $t_{\text {hitung }}>t_{\text {tabel, }}(2,411>2,04)$ dan Variabel Motivasi berpengaruh positif dan signifikan terhadap Kinerja Guru dengan nilai $t_{\text {hitung }}>t_{\text {tabel, }}(3,218>2,04)$. Secara Simultan variabel Lingkungan Kerja, Fasilitas Kerja dan Motivasi berpengaruh positif dan signifikan terhadap Kinerja Guru dengan nilai $F_{\text {hitung }}>$ $F_{\text {tabel, }}\left(14,558>2,87\right.$ ). Nilai $R^{2}$ (RSquare) sebesar 0.540, yang berarti bahwa variabel Lingkungan Kerja, Fasilitas Kerja dan Motivasi berpengaruh Positif dan signifikan terhadap Kinerja Guru di Yayasan Pendidikan Azadin Anhar Kecamatan Wampu Kabupaten Langkat sebesar 54,00\%, dan sisanya sebesar 46,00\% lagi, dipengaruhi oleh faktor-faktor lain yang tidak diteliti.

Kata Kunci : Lingkungan Kerja, Fasilitas Kerja, Motivasi dan Kinerja Guru

\section{Pendahuluan}

Berkembangnya suatu kualitas pendidikan tidak lepas dari peran kinerja para guru. Tanpa kinerja guru yang baik maka pencapaian kualitas pendidikan akan sulit untuk dicapai. Dalam hal ini peran pemerintah sangat diperlukan untuk peningkatan kinerja guru tersebut. Selain itu potensi kualitas pendidikan juga tidak bisa dikesampingkan, karena dua hal tersebut sangat penting untuk majunya pendidikan. Di Indonesia sendiri peran pemerintah direalisasikan dengan terbitnya undang-undang No 20 tahun 2003 tentang sistem pendidikan Nasional, yang mana untuk menata kembali (meratifikasi) dunia 
pendidikan indonesia guna lebih mempertajam kualitas pendidikan baik pada penataan kebijakan, penataan kelembagaan dan penataan tenaga kependidikan. Dalam rangka melaksanakan Undang-undang tersebut pemerintah megeluarkan peraturan PP No 19 Tahun 2004 tentang standart Nasional Pendidikan yang mencakup standart: isi, proses, kompetensi lulusan, pendidik dan tenaga pendidikan, sarana dan prasarana, pengelolaan pembiayaan dan standar penilaian pendidikan. Keberhasilan suatu pendidikan menurut penelitian dipengaruhi oleh faktor tenaga pendidikan (50\%), kurikulum (20\%), sarana dan prasaran (20\%), peserta didik $(10 \%)$.

Guru sebagai tenaga kependidikan merupakan salah satu faktor penentu keberhasilan tujuan pendidikan, karena guru yang langsung bersinggungan dengan peserta didik, untuk memberikan bimbingan yang akan menghasilkan tamatan yang diharapkan. Guru merupakan sumber daya manusia yang menjadi perencana, pelaku dan penentu tercapainya tujuan pendidikan. Untuk itu dalam menunjang kegiatan guru diperlukan iklim sekolah yang kondusif dan hubungan yang baik antar unsur-unsur yang ada di sekolah antara lain kepala sekolah, guru, tenaga administrasi dan siswa. Serta hubungan baik antar unsur-unsur yang ada di sekolah dengan orang tua murid/masyarakat.

Kinerja adalah tingkat keberhasilan seseorang atau kelompok orang dalam melaksanakan tugas dan tanggung jawabnya serta kemampuan untuk mencapai tujuan dan standar yang telah ditetapkan (Sulistyorini, 2001). Sedangkan Ahli lain berpendapat bahwa Kinerja merupakan hasil dari fungsi pekerjaan atau kegiatan tertentu yang di dalamnya terdiri dari tiga aspek yaitu: Kejelasan tugas atau pekerjaan yang menjadi tanggung jawabnya; Kejelasan hasil yang diharapkan dari suatu pekerjaan atau fungsi; Kejelasan waktu yang diperlukan untuk menyelesikan suatu pekerjaan agar hasil yang diharapkan dapat terwujud. Studi ini penting dilakukan karena melihat masih ada guru yang bekerja sampingan diluar sekolah, masih ada guru yang belum mengikuti pelatihan-pelatihan yang dilakukan untuk mengembangkan kemampuan dan ketrampilan guru, masih ada guru yang datang terlambat, tidak masuk mengajar tanpa ijin, guru yang mengajar tidak mempunyai persiapan mengajar atau ada persiapan mengajar namun tidak lengkap. Fenomena yang terjadi diatas bisa disebabkan oleh beberapa faktor, namun penulis hanya melihat dari faktor motivasi yang didasarkan pada teori Malsow yang terdiri dari kebutuhan fisiologis, kebutuhan kemanan, kebutuhan sosial, kebutuhan penghargaan dan kebutuhan aktualisasi diri.

Keberhasilan kinerja yang ditunjukkan guru. Akan tetapi dewasa ini banyak terjadi kepincangan pada sistem pendidikan, disebabkan pelaksanaan asas pendidikan yang kurang sempurna. Anehnya, walaupun guru-guru mempunyai ilmu dan pengalaman yang lengkap dalam teori-teori pelajaran, tetapi banyak dari mereka yang lari dari tanggung jawab pendidikan. Terdapat banyak guru yang tidak memperhatikan disiplin bekerja. Murid-murid dibiarkan saja bebas melakukan apa saja yang mereka mau. Keadaan ini terus-menerus berlangsung sepanjang hari. Akibatnya banyak murid lemah dalam masalah berfikir, membaca, dan menulis. Guru-guru biasanya sibuk dengan aktivitas mereka sendiri.

Lingkungan kerja yang menyenangkan bagi guru-guru melalui pengikatan hubungan yang harmonis dengan atasan, rekan kerja, maupun bawahan, serta didukung oleh fasilitas kerja yang memadai yang ada di tempat bekerja akan membawa dampak yang positif bagi guru, sehingga kinerja guru dapat meningkat. Dengan terciptanya lingkungan kerja yang kondusif, diharapkan kinerja guru juga akan meningkat. Kinerja guru berkaitan dengan prestasi kerja yang diukur berdasarkan kriteria yang ditetapkan oleh pihak manajemen sekolah. Kinerja yang tinggi akan memberikan pengaruh yang positif bagi keberlangsungan sekolah tersebut.

Selanjutnya disamping Lingkungan kerja, dalam proses belajar mengajar perlu didukung fasilitas kerja yang cukup. Untuk meningkatkan produktivitas kerja guru, perlu adanya fasilitas kerja yang baik. Fasilitas kerja merupakan suatu bentuk pelayanan sekolah terhadap guru agar menunjang kinerja dalam memenuhi kebutuhan guru, sehingga dapat meningkatkan produktifitas kerja guru. Adanya fasilitas kerja yang disediakan oleh sekolah sangat mendukung guru dalam bekerja. Fasilitas kerja tersebut sebagai alat atau sarana dan prasarana untuk membantu guru agar lebih mudah menyelesaikan pekerjaannya dan guru akan bekerja lebih produktif. Menurut jurnal dengan adanya fasilitas kerja guru akan merasa nyaman dalam bekerja dan menimbulkan semangat kerja untuk mendapatkan hasil yang diharapkan oleh sekolah. 


\subsection{Rumuasan Masalah}

Secara umum mutu pendidikan yang baik menjadi tolok ukur bagi keberhasilan kinerja yang ditunjukkan guru. Akan tetapi dewasa ini banyak terjadi kepincangan pada system pendidikan, disebabkan pelaksanaan asas pendidikan yang kurang sempurna, berdasarkan uraian diatas yang menjadi rumusan masalah dalam penelitian ini adalah : Bagaimana pengaruh Lingkungan Kerja, Fasilitas kerja dan Motivasi Kerja terhadap Kinerja Guru di Yayasan Pendidikan Azadin Anhar Kecamatan Wampu Kabupaten Langkat.

\subsection{Batasan Masalah}

Dari hasil permasalahan dalam penelitiani ini, maka penulis membatasi penelitian ini hanya pada Lingkungan kerja, Fasilitas kerja, Motivasi kerja dan Kinerja Guru di Yayasan Pendidikan Azadin Anhar Kecamatan Wampu Kabupaten Langkat.

\subsection{Hipotesa}

Berdasarkan rumusan masalah, tujuan penelitian, kajian teori, dan kerangka konseptual yang telah dikemukakan diatas, maka rumusan hipotesis penelitian ini dapat dirumuskan sebagai berikut : Lingkungan Kerja, Fasilitas kerja dan Motivasi Kerja secara simultan berpengaruh terhadap Kinerja Guru di Yayasan Pendidikan Azadin Anhar Kecamatan Wampu Kabupaten Langkat.

\subsection{Tujuan Penelitian}

Berdasarkan rumusan masalah yang di uraikan di atas, maka dalam Penelitian ini bertujuan untuk mengetahui :

1. Pengaruh Lingkungan Kerja terhadap Kinerja guru di Yayasan Pendidikan Azadin Anhar Kecamatan Wampu Kabupaten Langkat.

2. Pengaruh Fasilitas kerja terhadap Kinerja Guru di Yayasan Pendidikan Azadin Anhar Kecamatan Wampu Kabupaten Langkat.
3. Pengaruh Motivasi Kerja terhadap Kinerja Guru di Yayasan Pendidikan Azadin Anhar Kecamatan Wampu Kabupaten Langkat.

4. Pengaruh Lingkungan Kerja, Fasilitas kerja dan Motivasi Kerja terhadap Kinerja Guru di Yayasan Pendidikan Azadin Anhar Kecamatan Wampu Kabupaten Langkat.

\section{Metode Penelitian}

\subsection{Populasi dan Sampel}

Populasi adalah wilayah generasi yang terdiri dari atas objek/subjek yang mempunyai kualitas karakteristik tertentu yang disajikan oleh peneliti untuk dipelajari dan kemudian ditarik kesimpulannya. Berdasarkan definisi tersebut, maka populasi dalam penelitian ini adalah guruguru Yayasan Pendidikan Azadin Anhar Kecamatan Wampu Kabupaten Langkat yang berjumlah 37 orang.

Sampel adalah bagian dari populasi yang mempunyai peluang/estimasi yang sama untuk menjadi sampel. Apabila subjeknya kurang dari 100, lebih baik diambil seluruhnya sehingga penelitiannya merupakan penelitian populasi. Tetapi jika jumlah subjeknya lebih besar dari 100, maka dapat diambil sampel antara $10-15 \%$ atau 20-24\% atau lebih. Dengan demikian merujuk dari pernyataan diatas maka sampel dalam penelitian ini seluruh populasi yang berjumlah 37 orang guru yang disebut dengan metode total sampling.

\subsection{Uji Normalitas Data}

Uji normalitas data bertujuan untuk mengetahui apakah data yang digunakan dalam model regresi telah terdistribusi normal atau tidak. Alat uji yang digunakan dalam penelitian ini adalah uji Kolmogrov - Smirnov test. Data dinyatakan normal apabila nilai Kolmogorov Smirnov Z lebih kecil dari 1,97 $(\mathrm{Z}<1,97)$ dengan level asymp.sig (2tailed) $>$ Level signifikan $t$ $(5 \%)$

Tabel 1. Uji Kolmogorov Smirnov

One-Sample Kolmogorov-Smirnov Test

\begin{tabular}{|c|c|c|c|c|c|}
\hline & $\mathrm{X} 1$ & $\mathrm{X} 2$ & $\mathrm{X} 3$ & $\mathrm{Y}$ \\
\hline \multicolumn{2}{|l|}{$\mathrm{N}$} & & & & \\
\hline \multirow{2}{*}{ Normal Parameters ${ }^{\mathrm{a}, \mathrm{b}}$} & Mean & 36.2144 & 36.1482 & 36.3421 & 36.4755 \\
\hline & $\begin{array}{l}\text { Std. } \\
\text { Deviation }\end{array}$ & 0.32450 & 0.31745 & 0.32873 & 0.26435 \\
\hline \multirow{3}{*}{$\begin{array}{l}\text { Most Extreme } \\
\text { Differences }\end{array}$} & Absolute & .165 & .168 & .152 & 0.564 \\
\hline & Positive & .145 & .162 & .045 & .015 \\
\hline & Negative & -.025 & -.045 & -.031 &.-080 \\
\hline \multicolumn{2}{|l|}{ Kolmogorov-Smirnov Z } & 1.256 & 1.327 & 1.361 & .525 \\
\hline \multicolumn{2}{|l|}{ Asymp. Sig. (2-tailed) } & .078 & .160 & .179 & .082 \\
\hline
\end{tabular}

a. Test distribution is Normal.

b. Calculated from data. 
Dari tabel 4.11 diatas dapat dilakukan uji :

Kolmogorov - Smirnov Z $<1,97$

$\begin{array}{llc}\mathrm{X} 1 & = & 1,256<1,97 \\ \mathrm{X} 2 & = & 1,327<1,97 \\ \mathrm{X} 3 & = & 1,361<1,97 \\ \mathrm{Y} & = & 0,525<1,97\end{array}$

Asymp Sig (2Tailed) > Level Sig. 5\% $(0,05)$

$\begin{array}{llc}\mathrm{X} 1 & = & 0,078>0,05 \\ \mathrm{X} 2 & = & 0,160>0,05 \\ \mathrm{X} 3 & = & 0,179>0.05 \\ \mathrm{Y} & = & 0,082>0,05\end{array}$

Melihat hasil pengolahan data dengan bantuan program SPSS diatas maka dapat disimpulkan bahwa seluruh data dalam penelitian ini berdistribusi dengan normal.

\subsection{Uji Multikolinearitas}

Model regresi berganda harus terbebas dari multikolinearitas untuk setiap variabel independentnya. Identifikasi keberadaan multikolinearitas ini dapat didasarkan pada beberapa kriteria, yaitu: Nilai tolerance dan variance inflation faktor (VIF), dimana nilai VIF tidak lebih dari 10 dan nilai tolerance tidak kurang dari 0,1 .

Tabel 2. Uji Multikolinearitas Coefficients $^{\mathrm{a}}$

\begin{tabular}{|rr|r|r|}
\hline \multirow{2}{*}{ Model } & \multicolumn{2}{|c|}{ Collinearity Statistics } \\
\cline { 2 - 4 } & Tolerance & \multicolumn{1}{c|}{ VIF } \\
\hline \multirow{3}{*}{1} & X1 & .745 & 2.573 \\
& X2 & .655 & 3.825 \\
& X3 & .581 & 3.733 \\
\hline
\end{tabular}

a. Dependent Variable: $Y$

Hasil perhitungan pada Tabel 5.12, nilai tolerance memperlihatkan bahwa masing-masing variabel independent tidak ada yang memiliki nilai yang kurang dari 0,1 dan nilai VIF tidak lebih dari 10 yang berarti syarat ini terpenuhi.

\subsection{Uji Autokorelasi}

Untuk mengetahui apakah di dalam model penelitian tersebut terdapat autokorelasi antara sesama variabel bebas terhadap variabel terikat. Pengujian ini menggunakan nilai Durbin Watson.

Tabel 3. Uji Autokorelasi dengan Durbin-watson Model Summary ${ }^{b}$

\begin{tabular}{|l|r|r|r|r|r|}
\hline Model & \multicolumn{1}{|c|}{$\mathrm{R}$} & $\mathrm{R}$ Square & $\begin{array}{c}\text { Adjusted R } \\
\text { Square }\end{array}$ & $\begin{array}{c}\text { Std. Error of } \\
\text { the Estimate }\end{array}$ & $\begin{array}{c}\text { Durbin- } \\
\text { Watson }\end{array}$ \\
\hline 1 & $.735^{\mathrm{a}}$ & .540 & .512 & 8.152131 & 2.472 \\
\hline
\end{tabular}

b. Dependent Variable: $Y$

Dari hasil pengujian dengan menggunakan uji Durbin-Watson atas residual persamaan regresi diperoleh angka d-hitung sebesar 2,472. Sebagai pedoman umum Durbin-Watson berkisar 0 dan 4, jika nilai uji statistik Durbin-Watson lebih kecil dari satu atau lebih besar dari tiga, maka residuals atau eror dari model regresi berganda tidak bersifat independent atau terjadi autocorrelation. Jadi berdasarkan nilai uji statistik Durbin-Watson dalam penelitian ini berada diatas satu dan dibawah tiga $(2,472)$ sehingga tidak terjadi autocorrelation.

\section{Hasil dan Pembahasan \\ 3.1. Analisis Regresi Linier Berganda}

Kerangka hubungan antara $\left(\mathrm{X}_{1}, \mathrm{X}_{2}, \mathrm{X}_{3}\right.$ terhadap $Y$ ) dapat dibuat mealalui persamaan variabel sebagai berikut :

$$
\mathbf{Y}=\mathbf{a}+\mathbf{b}_{1} \mathbf{X}_{1}+\mathbf{b}_{2} \mathbf{X}_{2}+\mathbf{b}_{3} \mathbf{X}_{3}+e
$$

Untuk mengetahui koefisien jalur dapat dilihat dari nilai Beta pada tabel Coefficienst berikut :

Coefficients $^{\mathrm{a}}$

Tabel 4. Hasil Uji Regresi Linier

\begin{tabular}{|c|c|c|c|c|c|}
\hline \multirow[t]{2}{*}{ Model } & \multicolumn{2}{|c|}{$\begin{array}{c}\text { Unstandardized } \\
\text { Coefficients }\end{array}$} & $\begin{array}{c}\text { Standardized } \\
\text { Coefficients }\end{array}$ & \multirow[t]{2}{*}{$\mathrm{t}$} & \multirow[t]{2}{*}{ Sig. } \\
\hline & $\mathrm{B}$ & Std. Error & Beta & & \\
\hline \multirow{4}{*}{$\begin{array}{l}\text { (Constant) } \\
\text { Ling.Kerja }\end{array}$} & 3.854 & 0.564 & & 5.376 & .001 \\
\hline & .532 & .250 & .271 & 2.525 & .000 \\
\hline & .561 & .232 & .530 & 2.411 & .001 \\
\hline & .473 & .301 & .462 & 3.218 & .001. \\
\hline
\end{tabular}


Dari tabel berikut diketahui masing-masing koefisien dari tiap variabel, dan didapatan persamaan sebagai berikut :

$$
Y=3,854+0,532 X_{1}+0,561 X_{2}+0,473 X_{3}+e
$$

- Nilai konstanta sebesar 3,854 menyatakan bahwa jika Lingkungan Kerja, Fasilitas Kerja dan Motivasi diabaikan maka nilai Kinerja Guru di Yayasan Pendidikan Azadin Anhar Kecamatan Wampu Kabupaten Langkat sebesar 3,854 (asumsi faktor lain konstan).

- Koefisien $\mathrm{X}_{1}$ sebesar 0,532 menyatakan bahwa Lingkungan Kerja berpengaruh sebesar 0,532 atau sebesar 53,20\% terhadap Kinerja guru di Yayasan Pendidikan Azadin Anhar Kecamatan Wampu Kabupaten Langkat (asumsi faktor lain konstan).

Coefficients $^{\mathrm{a}}$

\begin{tabular}{|c|c|c|c|c|c|}
\hline \multirow[t]{2}{*}{ Model } & \multicolumn{2}{|c|}{$\begin{array}{l}\text { Unstandardized } \\
\text { Coefficients }\end{array}$} & $\begin{array}{l}\text { Standardized } \\
\text { Coefficients }\end{array}$ & \multirow[t]{2}{*}{$\mathrm{t}$} & \multirow[t]{2}{*}{ Sig. } \\
\hline & $\mathrm{B}$ & Std. Error & Beta & & \\
\hline \multirow{4}{*}{$\begin{array}{l}\text { (Constant) } \\
\text { Ling.Kerja } \\
\text { Fas.kerja } \\
\text { Motivasi }\end{array}$} & 3.854 & 0.564 & & 5.376 & .001 \\
\hline & .532 & .250 & .271 & 2.525 & .000 \\
\hline & .561 & .232 & .530 & 2.411 & .001 \\
\hline & .473 & .301 & .462 & 3.218 & .001 \\
\hline
\end{tabular}

a. Pengujian pengaruh variabel Lingkungan $\operatorname{Kerja}\left(\mathbf{X}_{1}\right)$ terhadap Kinerja Guru $(\mathbf{Y})$

Secara parsial uji statistik yang digunakan adalah uji t. hasil perhitungan SPSS berdasarkan tabel Coefficients, diperoleh nilai t hitung 2,525 dan $t$ tabel 2,042, ini berarti bahwa nilai t hitung $>$ nilai $t$ tabel $(2,525>2,042)$, dengan nilai signifikansi $0,000<0,05$ maka H01 ditolak dan Ha1 diterima. Hal ini berarti hipotesis diterima yaitu Lingkungan Kerja berpengaruh positif dan signifikan terhadap Kinerja Guru di Yayasan Pendidikan Azadin Anhar Kecamatan Wampu Kabupaten Langkat.

b. Pengujian pengaruh variabel Fasilitas Kerja (X2) terhadap Kinerja Guru (Y)

Secara parsial uji statistik yang digunakan adalah uji t. hasil perhitungan SPSS berdasarkan tabel Coefficients, diperoleh nilai t hitung sebesar 2,411dan t tabel 2,042, ini berarti bahwa nilai $t$ hitung > nilai $\mathrm{t}$ tabel $(2,411>2,042)$, dengan nilai signifikansi 0,001 <0,05 maka H01 ditolak dan Hal diterima. Hal ini berarti hipotesis diterima yaitu Fasilitas Kerja berpengaruh positif
- Koefisien $\mathrm{X}_{2}$ sebesar 0,561 menyatakan bahwa Fasilitas Kerja berpengaruh sebesar 0,561 atau sebesar 56,10\% terhadap Kinerja Guru di Yayasan Pendidikan Azadin Anhar Kecamatan Wampu Kabupaten Langkat (asumsi faktor lain konstan).

- Koefisien $\mathrm{X}_{3}$ sebesar 0,473 menyatakan bahwa Motivasi berpengaruh sebesar 0,473 atau sebesar 47,30 \% terhadap Kinerja Guru di Yayasan Pendidikan Azadin Anhar Kecamatan Wampu Kabupaten Langkat (asumsi faktor lain konstan).

\subsection{Pengujian Secara Parsial (Uji t)}

Untuk melihat besarnya pengaruh antara Lingkungan Kerja, Fasilitas Kerja dan Motivasi terhadap Kinerja Guru dan tingkat signifikansi secara parsial, digunakan uji t sebagai berikut : dan signifikan terhadap Kinerja guru di Yayasan Pendidikan Azadin Anhar Kecamatan Wampu Kabupaten Langkat.

\section{c. Pengujian pengaruh variabel Motivasi (X3) terhadap Kinerja Guru (Y)}

Secara parsial uji statistik yang digunakan adalah uji t. hasil perhitungan SPSS berdasarkan tabel Coefficients, diperoleh nilai t hitung sebesar 3,218 dan $\mathrm{t}$ tabel 2,04, ini berarti bahwa nilai $\mathrm{t}$ hitung > nilai t tabel $(3,218>2,042)$, dengan nilai signifikansi $0,001<0,05$ maka H01 ditolak dan Hal diterima. Hal ini berarti hipotesis diterima yaitu Motivasi berpengaruh positif dan signifikan terhadap Kinerja guru di Yayasan Pendidikan Azadin Anhar Kecamatan Wampu Kabupaten Langkat.

\subsection{Pengujian Secara Simultan (Uji - F)}

Pengujian hipotesis secara simultan diperlukan untuk mengetahui apakah variabel $\mathrm{X} 1, \mathrm{X} 2$ dan $\mathrm{X} 3$ secara bersama-sama berpengaruh terhadap variabel $(\mathrm{Y})$. 
Tabel 6. Hasil Uji - F

ANOVA $^{\mathrm{a}}$

\begin{tabular}{|c|c|c|c|c|c|c|}
\hline \multicolumn{2}{|c|}{ Model } & $\begin{array}{l}\text { Sum of } \\
\text { Squares }\end{array}$ & $\mathrm{df}$ & $\begin{array}{l}\text { Mean } \\
\text { Square }\end{array}$ & $\mathrm{F}$ & Sig. \\
\hline \multirow{3}{*}{1} & Regression & 1764.352 & 2 & 425.164 & 14.558 & $.000^{\mathrm{b}}$ \\
\hline & Residual & 1254.312 & 35 & 25.328 & & \\
\hline & Total & 3018.664 & 37 & & & \\
\hline
\end{tabular}

Pengujian hipotesis dilakukan dengan cara membandingkan besarnya angka $\mathrm{F}$ penelitian dengan $\mathrm{F}$ tabel, dengan kriteria sebagai berikut:

Jika $\mathrm{F}_{\text {hitung }}>\mathrm{F}_{\text {tabel }}$, maka $\mathrm{H}_{0}$ ditolak dan $\mathrm{Ha}$ diterima

Jika $\mathrm{F}_{\text {hitung }}<\mathrm{F}_{\text {tabel}}$, maka $\mathrm{H}_{0}$ diterima dan $\mathrm{Ha}$ ditolak

Berdasarkan tabel 5.16, angka $\mathrm{F}$ penelitian yang diperoleh dari hasil perhitungan adalah sebesar 14.558 Sedangkan angka $F$ tabel dihitung dengan taraf signifikansi 95\% dan alpha 5\% serta derajat kebebasan (dk) dengan ketentuan $\mathrm{dk}=\mathrm{n}-2$ atau 37-2 $=35$, maka diperoleh angka Ftabel $=$ 2,87 .

Dengan demikian nilai $\mathrm{F}_{\text {hitung }}=14.558>\mathrm{F}_{\text {tabel }}$ $=2,87$, dengan nilai signifikansi $0,00<0,05$. karena $\mathrm{F}_{\text {hitung }}>\mathrm{F}_{\text {tabel }}$ yang berarti bahwa $\mathrm{H}_{0}$ ditolak dan $\mathrm{Ha}$ diterima, sehingga dapat disimpulkan bahwa Lingkungan Kerja, Fasilitas Kerja dan Motivasi berpengaruh positif dan signifikan terhadap Kinerja guru di Yayasan Pendidikan Azadin Anhar Kecamatan Wampu Kabupaten Langkat.

\subsection{Uji Determinasi $\left(\mathbf{R}^{2}\right)$}

Uji Determinasi dilakukan untuk mengetahui berapa besar pengaruh atau kontribusi variabel bebas terhadap variabel terikat yaitu Fasilitas Belajar (X1), Disiplin (X2) dan Lingkungan Kerja secara bersama-sama terhadap Kinerja guru (Y). Pengujian ini menggunakan nilai Koefisien determinasi atau $\mathrm{R}$ square $\left(\mathrm{R}^{2}\right)$.

Tabel 7. Uji Determinasi

Model Summary ${ }^{b}$

\begin{tabular}{|l|r|r|r|r|r|}
\hline Model & $\mathrm{R}$ & $\mathrm{R}$ Square & $\begin{array}{c}\text { Adjusted R } \\
\text { Square }\end{array}$ & $\begin{array}{c}\text { Std. Error of } \\
\text { the Estimate }\end{array}$ & $\begin{array}{l}\text { Durbin- } \\
\text { Watson }\end{array}$ \\
\hline 1 & $.735^{\mathrm{a}}$ & .540 & .512 & 8.152131 & 2.472 \\
\hline
\end{tabular}
a. Predictors: (Constant), $X 1, X 2, X 31$ Dependent Variable: $Y$

Berdasarkan tabel diatas didapat nilai $\mathrm{R}$ Square sebesar 0.540 atau 54,00 \%. Maka dapat dijelaskan bahwa variabel Lingkungan Kerja (X1), Fasilitas Kerja (X2) dan Motivasi (X3) berpengaruh sebesar 54,00\% terhadap Variabel Kinerja Guru di Yayasan Pendidikan Azadin Anhar Kecamatan Wampu Kabupaten Langkat, sisanya sebesar 46,00\% lagi dipengaruhi oleh Variabel lain yang tidak diikutkan dalam penelitian.

\section{Kesimpulan}

Dari pembahasan hasil penelitian diatas, maka dapat diambil beberapa kesimpulan dan saran sebagai berikut :

a. Variabel Lingkungan Kerja berpengaruh positif dan signifikan terhadap Kinerja Guru di Yayasan Pendidikan Azadin Anhar Kecamatan Wampu Kabupaten Langkat, dengan nilai t hitung > nilai t tabel $(2,525>$ 2,042 ) dan pengaruhnya sebesar 0,532 atau $53,20 \%$.

b. Variabel Fasilitas Kerja berpengaruh positif dan signifikan terhadap Kinerja Guru di di Yayasan Pendidikan Azadin Anhar Kecamatan Wampu Kabupaten Langkat, dengan nilai t hitung > nilai t tabel $(2,411>$ 2,042 ) dan pengaruhnya sebesar 0,561 atau $56,10 \%$.

c. Variabel Motivasi berpengaruh positif dan signifikan terhadap Kinerja Guru di Yayasan Pendidikan Azadin Anhar Kecamatan Wampu Kabupaten Langkat, dengan nilai $t$ hitung > nilai t tabel $(3,218>2,042)$ dan pengaruhnya sebesar 0,473 atau $47,30 \%$.

d. Variabel Lingkungan Kerja, Fasilitas Kerja dan Motivasi berpengaruh positif dan signifikan terhadap Kinerja Guru di Yayasan 
Pendidikan Azadin Anhar Kecamatan Wampu Kabupaten Langkat, dengan nilai $\mathrm{F}$ hitung > nilai $\mathrm{F}$ tabel $(14,558>2,87)$ dan pengaruhnya sebesar 0,540 atau $54,00 \%$.

\section{DAFTAR PUSTAKA}

Ahmadi, Abu. (2007). Sosiologi pendidikan. Jakarta : PT Rineka Cipta

Arikunto, S (2002). Dasar-Dasar Evaluasi Pendidikan (Edisi Rrevisi). Jakarta:Bumi Aksara.

Arikunto,S. (2006).Prosedur Penelitian Suatu Pendekatan Praktik. Jakarta: Rineka Cipta.

Bimo Walgito. 1997. Pengantar Psikologi Umum. Yogyakarta: Andi Ofset.

B. Suryosubroto. 2004. Manajemen Pendidikan di Sekolah. Jakarta: Rineka Cipta.

Buchori. (1991). Psikologi Pendidikan. Jakarta. PT. Aksara Baru.

Chaplin, James P. (2002 ).Kamus Psikologi. Jakarta : Rajawali

Christpher Pass dan Bryan Lowes. 1994. Kamus Lengkap Ekonomi,. Jakarta: Erlangga,

Departemen Pendidikan Nasional. (2005). Kamus besar bahasa indonesia. Jakarta. Balai Pustaka.

Djaali. (2011). Psikologi Pendidikan. Jakarta : Bumi Aksara.

Djamarah, Syaiful Bahri. ( 2008 ). Psikologi belajar. Jakarta: Rineka Cipta

E. Mulyasa. 2004. Kurikulum Berbasis Kompetensi. Bandung: Remaja Rosdakarya.

........... 2007. Menjadi Kepala Sekolah Profesional. Bandung: PT Remaja Rosdakarya..

2008. Menjadi Guru Profesional. Bandung: PT Rosdakarya.

Eti Rochaety, dkk. 2005. Sistem Informasi Manajemen Pendidikan. Jakarta: Bumi Aksara.

Farida Hanum. 2011. Sosiologi Pendidikan. Yogyakarta: Kanwa Publisher.

Ibrahim Bafadal. 2003. Manajemen Peningkatan Mutu Pendidikan Berbasis Sekolah, Manajemen Perlengkapan Sekolah Teori dan Aplikasi. Jakarta: Bumi Aksara.

Jalaludin Rakhmat. 2003. Psikologi Komunikasi. Bandung: Remaja Rosdakarya.

Gie, The Liang ( 1995 ). Cara belajar Yang Efisien. Yogyakarta : Liberty

Kadariyah (2001), Analisa Pendapatan Nasional, Jakarta: Bina Aksara,

Kurjono. (2010). Proses belajar Mengajar dengan Aspek-aspeknyna Panduan bagi Para
Pendidik, Mahasiswa dan Para Praktisi Pendidikan. Bandung: ProgramStudi Pendidikan Akuntansi: Tidak diterbitkan.

Miftah Thoha. 1996. Perilaku Organisasi. Jakarta: Rajawali.

Mudrajat Kuncoro. 2001. Metode Kuantitatif. Yogyakarta: Unit penerbit dan percetakan AMP YKPN

Mulyasa, E. 2008. Standar Kompetensi dan Sertifikasi Guru. Bandung: PT. Remaja Rosda Karya.

Muhaimin. 2003. Pengembangan Kurikulum PAI di Sekolah-sekolah dan Perguruan Tinggi. Jakarta: Raja Grafindo Persada.

Muhibin Syah. 2005. Psikologi Pendidikan. Bandung: Rosdakarya.

Notodiharjo, Hardjono, (1990). Pendidikan tinggi dan tenaga kerja tingkat tinggi di Indonesia. Jakarta : Universitas Indonesia

Peraturan Menteri Pendidikan Nasional Nomor 13 Tahun 2007 tentang Standar Kompetensi Kepala Sekolah.

Sujanto, Agus. (2004). Psikologi Umum. Jakarta: PT. Rineka Cipta

Saifuddin Azwar.2012. Penyusunan Skala Psikologi. Yogyakarta: Pustaka Pelajar.

Sobri, dkk. 2009. Pengelolaan Pendidikan. Yogyakarta: Multi Pressindo.

Supardi dan Anwar. 2002. Motivasi Kerja.Puri Arsita Anam. Yogyakarta.

Usman, M.U. 2003. Menjadi Guru Profesional. Bandung: Remaja Rosdakarya.

Undang-undang Republik Indonesia Nomor 14 tahun 2005 Tentang Guru dan Dosen. Surabaya : Kesindo Utama

Winkel.(2005). Psikologi Pengajaran. Yogyakarta: Media Abad

Widjaya, Cece. 1991. Kemampuan Dasar Guru dalam Proses Belajar Mengajar. Bandung: Rosda Karya 